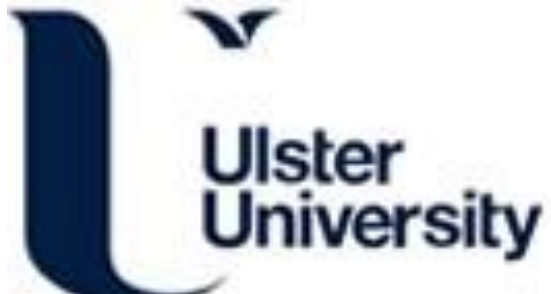

Role of interlayer spacing and functional group on the hydrogen storage properties of graphene oxide and reduced graphene oxide

Rajaura, R. S., Srivastava, S., Sharma, V., Sharma, P. K., Lal, C., Singh, M., Palsania, H. S., \& Vijay, Y. K. (2016). Role of interlayer spacing and functional group on the hydrogen storage properties of graphene oxide and reduced graphene oxide. International Journal of Hydrogen Energy, 41(22), 9454-9461.

https://doi.org/10.1016/j.ijhydene.2016.04.115

Link to publication record in Ulster University Research Portal

\section{Published in:}

International Journal of Hydrogen Energy

Publication Status:

Published (in print/issue): 15/06/2016

DOI:

10.1016/j.ijhydene.2016.04.115

\section{Document Version}

Author Accepted version

\section{General rights}

Copyright for the publications made accessible via Ulster University's Research Portal is retained by the author(s) and / or other copyright owners and it is a condition of accessing these publications that users recognise and abide by the legal requirements associated with these rights.

\section{Take down policy}

The Research Portal is Ulster University's institutional repository that provides access to Ulster's research outputs. Every effort has been made to ensure that content in the Research Portal does not infringe any person's rights, or applicable UK laws. If you discover content in the Research Portal that you believe breaches copyright or violates any law, please contact pure-support@ulster.ac.uk. 


\title{
Role of interlayer spacing and functional group on the hydrogen storage properties of
}

\section{Graphene oxide and reduced Graphene oxide}

\author{
Rajveer Singh Rajaura ${ }^{1,2 *}$, Vinay Sharma ${ }^{2}$, Preetam K. Sharma ${ }^{1}$, S. Srivastava ${ }^{3}$, C.L. Saini ${ }^{1}$, \\ Mangej Singh ${ }^{1}$, H. S. Palsania ${ }^{1}$, Y.K.Vijay ${ }^{3}$ \\ ${ }^{1}$ Department of Physics, University of Rajasthan, Jaipur 302004, India \\ ${ }^{2}$ Centre for Converging Technologies, University of Rajasthan, Jaipur 302004, India \\ ${ }^{3}$ Department of Physics, Vivekananda Global University, Jaipur 303905, India
}

\begin{abstract}
Hydrogen storage properties of the derivatives of graphene, graphene oxide/reducedgraphene oxide are studied in this paper. Modified Hummer's method was adopted for synthesis of graphene oxide (GO) and reduced-graphene oxide (rGO). The morphology of GO/rGO was examined by scanning electron microscopy (SEM) and transmission electron microscopy (TEM). The presence of $\mathrm{C}=\mathrm{O}$ and $-\mathrm{OH}$ group in the Fourier transform infrared (FTIR) spectrum and Gmode and 2D-mode in the micro-Raman studies confirmed the synthesis of the GO and rGO. Furthermore, the structural investigations using powder $x$-ray diffraction (XRD) reveals the hexagonal crystallographic phase of $\mathrm{GO} / \mathrm{rGO}$. The hydrogen storage capacity of the GO/rGO sample is measured using indigenously fabricated high pressure hydrogen storage Sieverts' type volumetric setup at room temperature and pressure up to 80 bars. In present experimental investigations, $\mathrm{GO}$ was found to exhibit better $\mathrm{H}_{2}$ uptake capacity (1.90wt. \%) as compared to rGO (1.34 wt. \%) at room temperature. It can be said that the oxygen functional groups work as spacers in between the graphene layers and increase the inter-layer space which in turn accumulate more number of hydrogen molecules on surface of carbon nano-sheets.
\end{abstract}

“Corresponding author. Tel.: +91-8233360533. Email Address: rajveer.nano_cct@live.com (R.S. Rajaura), mangej_singh@yahoo.com (Mangej Singh). 


\section{INTRODUCTION}

The air pollution and toxic emissions play key role in controlling global temperature which leads to category 4 and 5 hurricanes in the Atlantic Ocean [1]. In this context, pollution and climate change induced by the combustion products of currently used fuels add urgency for the development of environmentally clean fuels. Among all kinds of energy sources, hydrogen is found to be best choice as a clean fuel. It is a renewal, environment friendly, efficient, long life with less maintenance, and no greenhouse gas emission [2]. It also possesses unique qualities of being light weight, nontoxic and most abundant element in the universe. However, hydrogen doesn't occur naturally as a gas on the earth, and readily combines with other elements like water, hydrocarbon etc. Therefore, utilization of molecular hydrogen as energy carrier, its production, storage, and detection is necessary[3].

Presently, hydrogen is stored in three ways namely (a) high pressure, (b)cryogenic,(c) solid state hydrogen storage [4]. The high pressure hydrogen storage is an energy consuming process which needs a very high pressure (800 bars), high mechanical strength, large volume (88.89 cubic meters) piston pump to get enough hydrogen fuel for a driving .This may also lead to safety related issues if there is any automobile accident, explosion, and flammability [5]. In case of low temperature hydrogen storage, large amount of electrical energy for liquefaction (33K) and its inevitable boiling rate, make this method not suitable for automobile application [5]. Therefore, solid state hydrogen storage $[6,7]$ technique seems promising in which hydrogen can be stored by three process namely (a) chemical absorption in which hydrogen react with the solid material to form new compound[8], (b) composite Polymer/metal materials in which transition metals are dispersed in polymer[9], (c) physical adsorption in which hydrogen is physically bonded to the surface of the material. The most studied material for physical absorption storage is carbon 
containing material such as metal organic frame work, carbon nanotube, graphite Nano fiber and other carbon nanostructure. The main reason for using nanostructured carbon is that it has high surface area, tunable pore structure, fast kinetics, low-density, high storage capacity, high mechanical strength and durability [10]. The U.S department of energy set targets for gravimetric volumetric hydrogen storage are $6.0 \mathrm{wt} . \%$ and $45 \mathrm{gH}_{2} / \mathrm{l}$ for year 2010 which is later on revised to 9.0 wt. $\%$ and $81 \mathrm{H}_{2} / /$ for year 2015 , respectively[11].

In 2004 Graphene was associated with carbon family by Geim and Novoselov which is a single layer of graphite that revealed many of the superior properties of this first ever isolated twodimensional (2-D) structure[12]. It is proposed as a potential candidate for hydrogen storage due to its higher specific surface $\left(2630 \mathrm{~cm}^{2} / \mathrm{gm}\right)$ and large Young's modulus (1.0 Tpa), in comparison to other carbon structures $[13,14]$. Reported value of hydrogen storage capacity for Graphene is about to be $1.2 \mathrm{wt} . \%$ and 0.1 wt. \% under a pressure of 10 bars at $77 \mathrm{~K}$ and $298 \mathrm{~K}$, respectively [18].However, Hau Kun Liu et al [19] showed 0.9 wt. \% and 1.2 wt. \% of hydrogen uptake capacity of MWCNT and GO at room temperature under the pressure of $5 \mathrm{MPa}$, respectively. A linear relationship between the hydrogen adsorption capacity and the graphene surface area was reported by Ghosh et al. [20]. However, Tildrinet al[21] reported that the $0.2 \mathrm{wt} . \%$ of hydrogen uptake in $\mathrm{GO}$ at $77 \mathrm{~K}$ under pressure of $1 \mathrm{bar}$ and room temperature. Haejin Kim [22] obtained a hydrogen uptake capacity of $4.8 \mathrm{wt} \%$ and $0.49 \mathrm{wt} \%$ by graphene oxide under $77 \mathrm{~K}$ and $298 \mathrm{~K}$ and $9 \mathrm{MPa}$. Hydrogen storage capacity $1.36 \mathrm{wt} \%$ and $1.26 \mathrm{wt} \%$ of graphene oxide wrapped with $\mathrm{V}_{2} \mathrm{O}_{5}$ and $\mathrm{TiO}_{2}$ under pressure $7 \mathrm{MPa}$ at $77 \mathrm{~K}$ temperature respectively, was observed [23]. 
In this paper, we are reporting the role of structural and chemical properties of Graphene oxide (GO) and reduced Graphene oxide (rGO) for its hydrogen storage applications. The enhancement of storage capacity $(1.34 \mathrm{wt}$. \% to $1.90 \mathrm{wt} . \%)$ in GO is explained on the basis of increase in the interlayer spacing between the graphene layers by the attachment of functional groups on graphene nanosheet that work as spacers, confirmed by the Raman and FTIR investigations.

\section{EXPERIMENTAL}

\subsection{Synthesis of Graphene oxide and reduced Graphene oxide}

Graphene oxide is synthesized using a well-documented modified Hummer's method [24, 25].

The starting materials for synthesis of graphene oxide were graphite powder $(<45 \mu \mathrm{m})$, potassium permanganate $\left(\mathrm{KMnO}_{4}\right)$, sodium nitrate $\left(\mathrm{NaNO}_{3}\right)$, hydrogen peroxide $\left(\mathrm{H}_{2} \mathrm{O}_{2}\right)(30 \%)$, and concentrated sulfuric acid $\left(\mathrm{H}_{2} \mathrm{SO}_{4}\right)$. The graphite powder $(3 \mathrm{~g})$ and sodium nitrate $(2 \mathrm{~g})$ are stirred in $70 \mathrm{~mL}$ of sulfuric acid at a temperature of $0^{\circ} \mathrm{C}$. After that, potassium permanganate $(9$ g) is slowly and carefully added in the mixture while the temperature is kept below $20^{\circ} \mathrm{C}$. After that, the ice bath is removed from the reaction flask. The flask is allowed to warm up to room temperature and again stirred for 15 minutes. Now, deionizer water $(250 \mathrm{~mL})$ is slowly added and temperature of the reaction must be below $100^{\circ} \mathrm{C}$. The reaction is stirred for 15 min before adding $400 \mathrm{ml}$ of deionized water. After that $30 \%$ of hydrogen peroxide are added to the solution and then left to stir for 24 hours. Now, the solution is separated by centrifugation at 7000 rotations per minute (rpm) using a rotary centrifuge. Brown pasty material of GO was obtained. GO was weighed to make colloidal dispersion in distilled water with continuous stirring at a temperature of $35^{\circ} \mathrm{C}$. A solution of hydrazine hydrate $\left(\mathrm{H}_{2} \mathrm{O}_{4}\right)$ was then added in the above solution as a reducing agent and stirred for $3 \mathrm{hr}$ at 60 . After this, the filtrate turned from 
brown to black and was again filtered to obtain a black material of reduced Graphene Oxide [24, 26-27].

\subsection{Characterization of $G O$ and $r G O$}

TEM characterization was performed with (FEI Techni G20-stwin) microscope with an accelerating voltage of $200 \mathrm{kV}$. The samples were prepared by sonicating the powder for $2 \mathrm{~min}$ and then placing a few drops on carbon-coated copper grid and then dried in air before examination. The SEM analysis was then carried out using a scanning electron microscope (SEM Carl Zeiss evo-18), operating at a voltage of $20 \mathrm{kV}$.For SEM analysis the fracture surface of samples was plated with a thin layer of gold before the scanning. The advanced D-8 x-ray diffractometer (acquired from Bruker AXS Germany) having $\mathrm{Cu} \mathrm{K} \alpha$ conventional X-ray source is used to for XRD analysis of the samples. Raman measurement was performed on an in-situ micro Raman (Renishaw, UK) spectroscopy with excitation laser beam wavelength of $514.5 \mathrm{~nm}$. The powder of GO and rGO were placed on the glass slide that was used for Raman system. Fourier-transform infrared (FTIR) spectra were obtained, in the range of $0-4500 \mathrm{~cm}^{-1}$, using a Shimadzu (FT-IR model 810 1A) spectrometer (KBr pellets).

\subsection{Hydrogen Storage Setup}

Hydrogen adsorption isotherms were measured by indigenous fabricated volumetric apparatus working under pressure 80 bar regions. The system is made by the stainless steel and brass because stainless steel is anticorrosive, non-sensitive to hydrogen gas and of high mechanical strength. B-series ball valves, A-lock fitting, and cross fitting are used as the leak proof of the system. Pressure transducer is used to measure the accurate pressure having maximum capacity of 100bar due to safety precautions. Computer controlled interface program is providing the accurate raw data between pressure v/s time. The configuration, elemental units, detailed design, 
various tests and operation of the built instrument are similar to those reported by Yang et al. [28]. The schematic representation of apparatus is shown in Fig.1. Prior to the measurement, the GO and rGO samples were degassed under rotary vacuum $\left(10^{-2}\right.$ tor $)$ at room temperature.

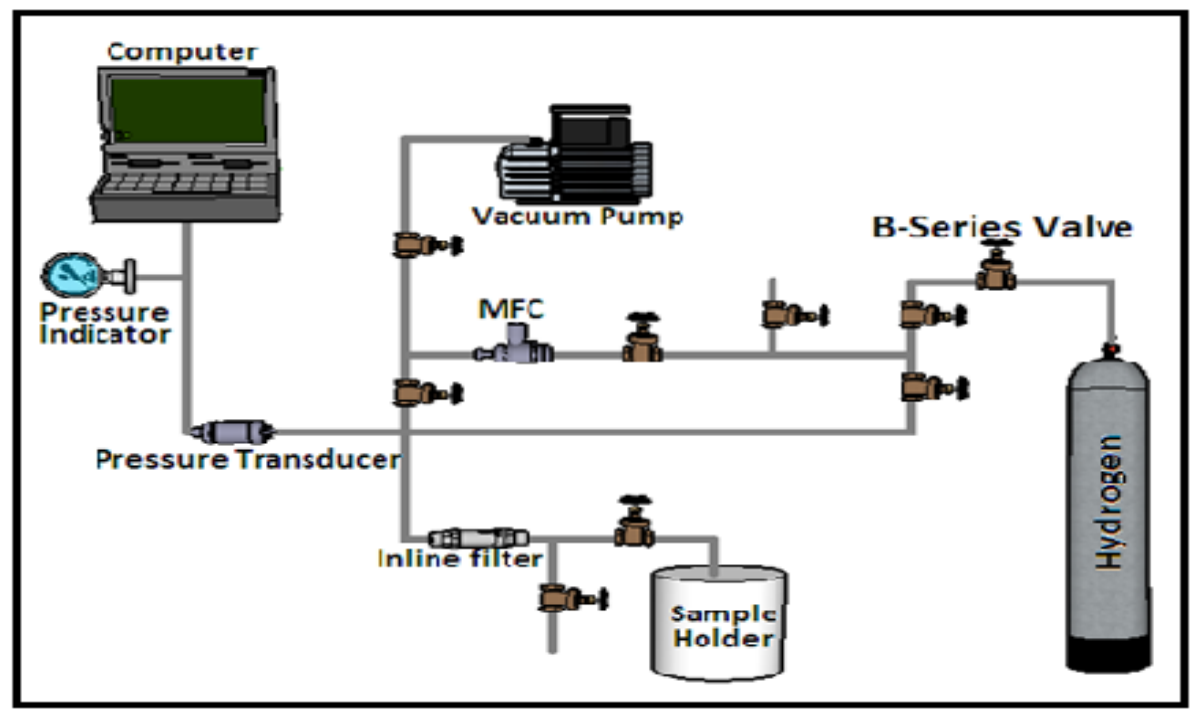

Fig.1 Schematic diagram of Seiverts' type volumetric hydrogen storage system.

The volumes of sample cells for high-pressure system were precisely measured for calibrations. Hydrogen adsorption was determined by exposing the samples to hydrogen gas at pressure 80 bar for six times.

\section{RESULTS AND DISCUSSION}

The SEM micrographs of the as-synthesized (a) GO, and (b) rGO are shown in figure 2. In case of GO sample, conjugated ribbon like highly wavy constitution with big wrinkle (red circle area) and small wrinkle (blue circle area) are observed. It may be also noted that features marked as red circle exhibits higher roughness than features represent in blue circle[29]. The difference in color contrast in SEM is observed due to variation in surface topography of GO, and number of 
GO layer in the sample. The darker region is corresponding to multiple layers whereas lighter region corresponds to very few layered of Graphene[30-32].
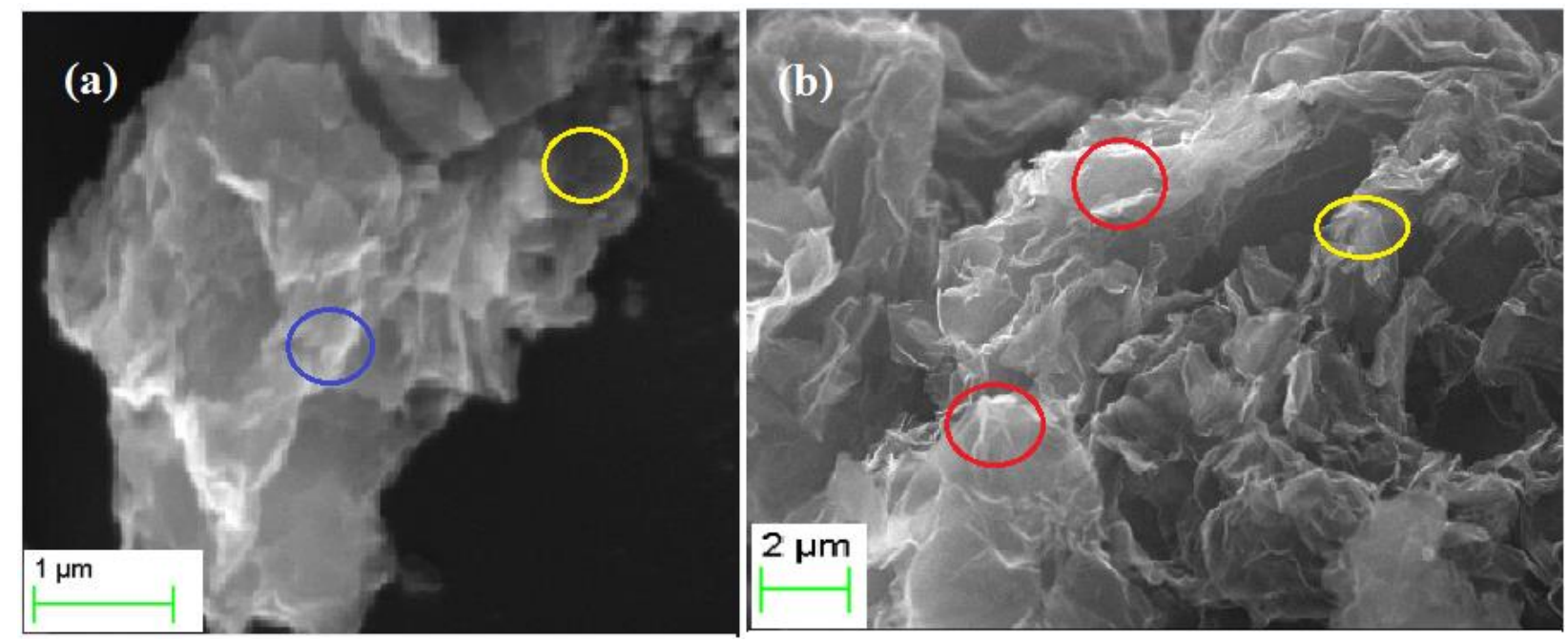

Fig.2 SEM images of as-prepared (a) Graphene oxide, and (b) reduced graphene oxide. The difference in contrast Fig. 2(a) is observed due to the variation in the number of layers. Highly conjugated ribbon morphology with big and small wrinkles is indicated in red and yellow circle in Fig. 2(b).

The surface structure at the nanoscale is further investigated using TEM studies. The HR-TEM images of the GO samples are shown in figure 3(a-d). In case of GO, wrinkle Graphene sheet covered with ribbon like regular carbon structure similar to SEM images are observed. Such morphology of graphene oxide can be attributed to the bonding between the inter layer graphene sheets by various functional groups and presence of stress and defect in the GO during the solution processing and drying[33]. The bright (blue circle) and dark (red circle) image contrast of graphene oxide in Fig. 3(a) is appeared due to variation in the surface topography of graphene oxide, as result of variation in density of electrons. The staircase sheet like structure (red arrow line) in Fig.3(b), is corresponding to graphene nanosheets. The high resolution image of GO 
provide the exact atomic structure of the GO Fig 3(c \& d).Diverse region of image is marked by the color in the fig.3(c). It is shown the small area of the GO is shown the well regular crystalline graphene layer with hexagonal lattice which is indicated by the indigo color in fig.3(c).The calculated value of distance of the hexagonal lattice is about $10.35 \mathrm{~nm}$. However, small amount of topological defects are also visible. This may be due to disordered few layer carbon nanosheets having amorphous carbon content due to the chemical oxidation which is indicated by yellow circle area in fig. 3(c)[34]. Dark lines near the edges of graphene oxide indicate that layer thickness is approximately 5 to $8 \mathrm{~nm}$ Fig. 3(d), as indicated by the red arrow line. The diamond shape indicates strong deformation in lattice by the agglomeration of graphene layers during the reaction process[35].
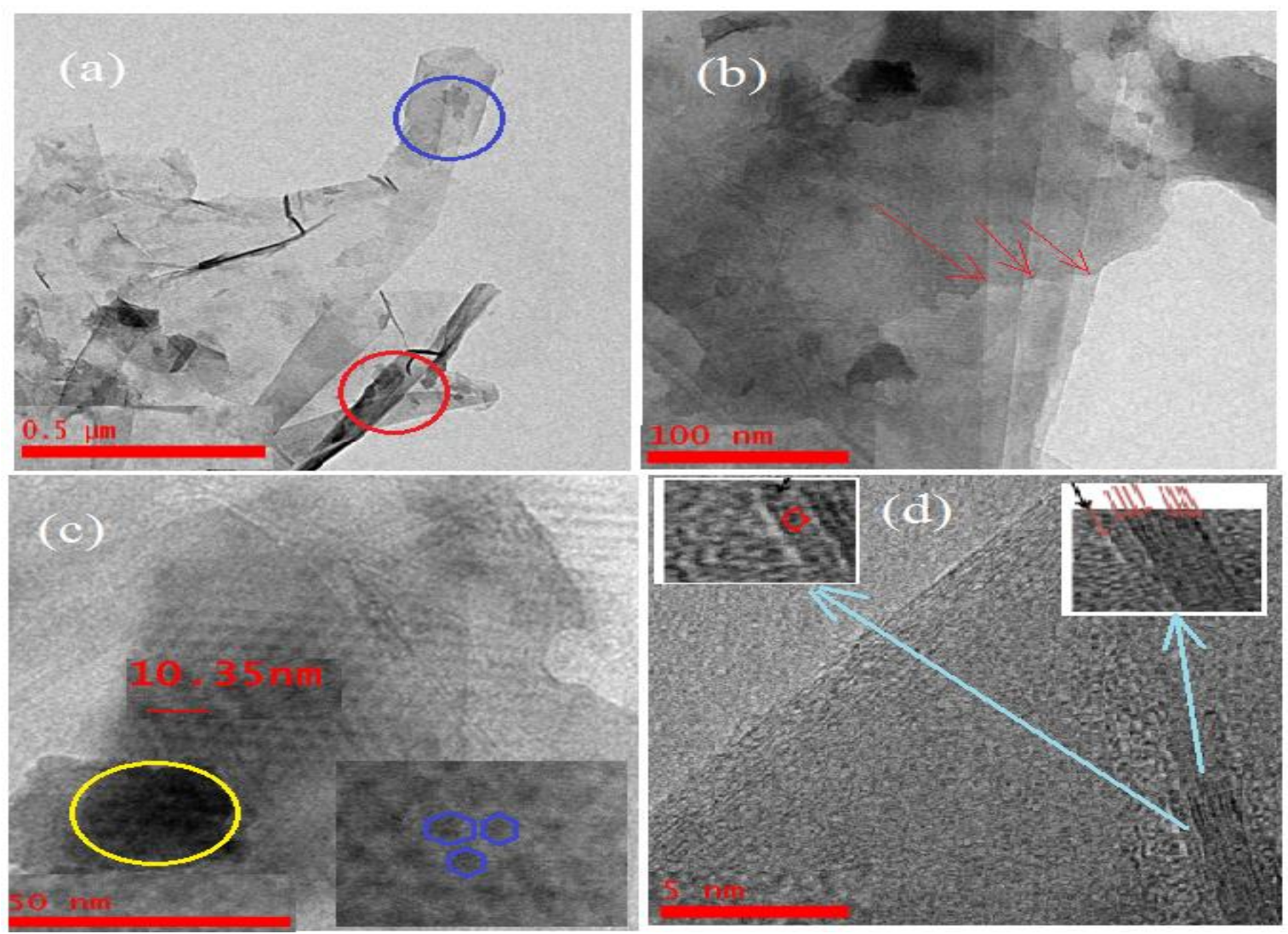
Fig. 3.TEM images of as-synthesized graphene oxide. (a) wrinkled, and (b) nano-sheet like morphology of graphene oxide are observed. In image (b), red arrow line indicates the graphene nano-sheet, whereas, high resolution image (c) showing regular graphene oxide with perfectly flat hexagonal lattice. The yellow circle indicates disorder of few layer carbon nano sheets in fig (c). The dark lines near the edge of graphene oxide in image (d) are indicating the layer thickness. Diamond shape in image(d) indicates strong deformation in the lattice of graphene layer.

The XRD pattern of the graphite is shown in Fig.4. Most intense peak in the pristine graphite is appearing at $2 \theta=26.32^{\circ}$ which is corresponding to (002) plane of graphite and interlayer spacing is about to $3.39 \mathrm{~A}^{\circ}$.

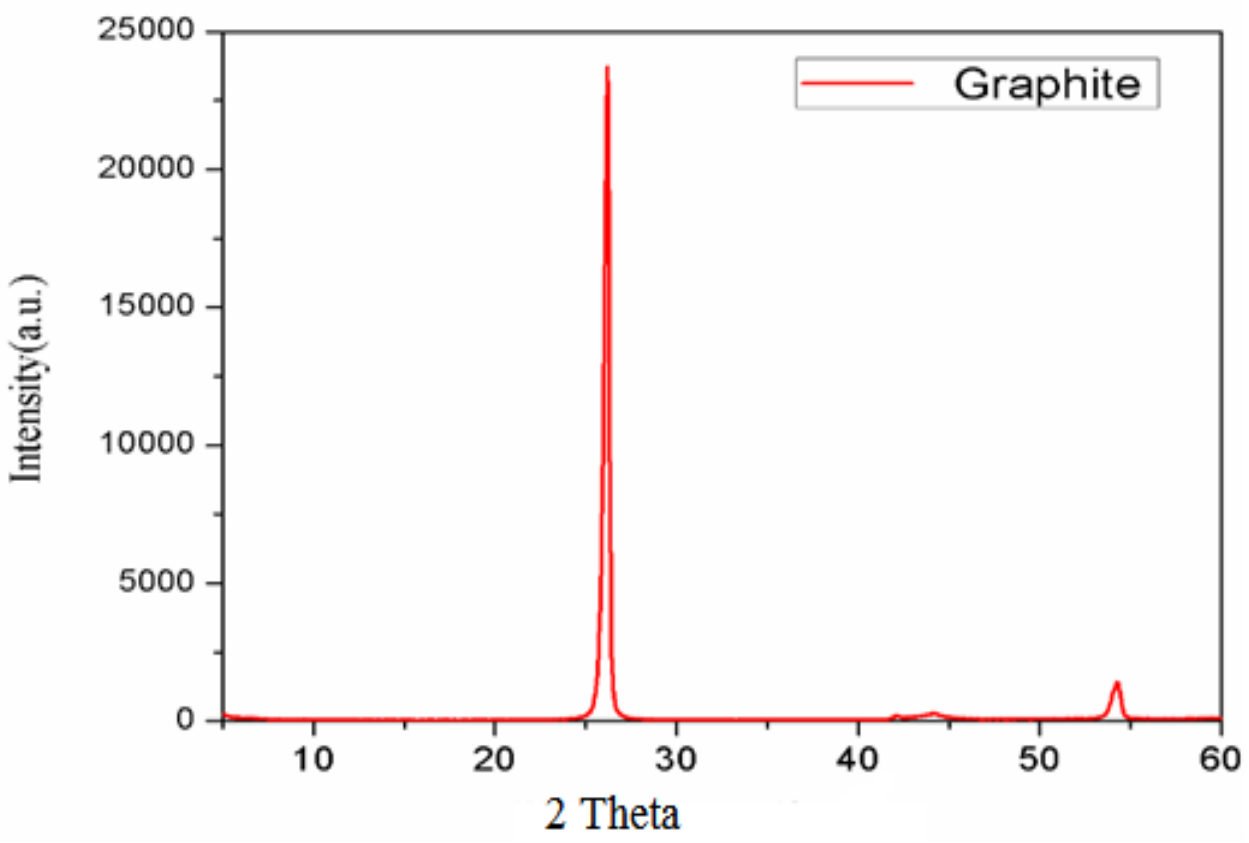

Fig. 4.XRD pattern of the graphite. 
Figure 5 shows the XRD pattern of the GO, rGO and hydrogenated rGO. The most prominent peak of GO sample is appearing at $2 \theta=9.96^{\circ}$ which is corresponding to the interlayer spacing $8.84 \mathrm{~A}^{\circ}[36]$.This facilitates the overture of the oxygen functional group and water moisture via chemical oxidation. This phenomenon leads to increase the inter layer space in the graphite layer which results in increasing the porosity that makes it an effective material for hydrogen storage. It may be noted that strongest peak of pristine graphite is also disappearing and sample is changing to the Graphene oxide. After the chemical reduction by hydrogen, a new broad peak is appearing at $2 \theta=23.72^{0}$ which corresponds to inter layer spacing of $3.85 \mathrm{~A}^{\circ}[37]$. This is attributed to the removal of functional group and moisture by chemical and thermal reduction. To investigate the effect of hydrogen storage on the crystal structure of the GO, XRD pattern is recorded in hydrogen gas atmosphere at gas pressure of 1000 mbar using in-situ XRD facility [38]. The (002) peak in case of hydrogenated graphene oxide is appearing at $2 \theta=12.20^{\circ}$ and inter layer distance $7.1 \mathrm{~A}^{\circ}$.

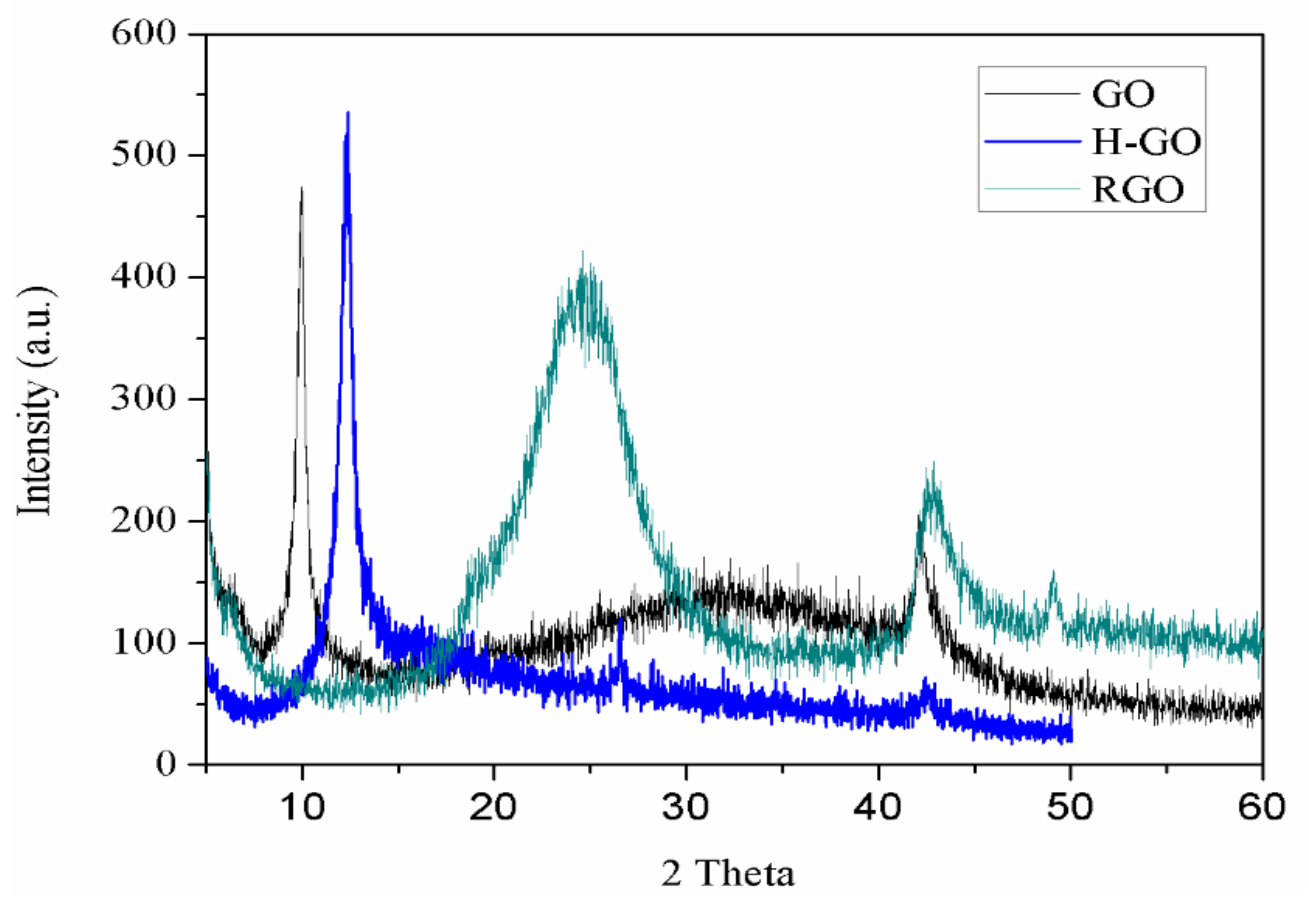


Fig. 5. XRD pattern of GO, $\mathrm{rGO}$ and and GO exposed to hydrogen gas at a pressure of the 1000 mbar.

This shows that d-spacing for the hydrogenated graphene oxide is lower than that of pristine graphene oxide. This confirms that the lattice strain is relaxed in the graphene oxide due to hydrogenation. The possible reason could be the reduction of the GO and absorbed of hydrogen on the surface GO on exposure to hydrogen gas. It can also be clearly seen that intensity of the hydrogenated GO is higher than as-synthesized GO. This is indicating that crystalline nature of the graphene oxide is improved on the hydrogenation.

Raman spectroscopy is an important technique for characterization of $\mathrm{sp}^{2}$ and $\mathrm{sp}^{3}$ hybridization of carbon atoms, including those in graphite, GO and rGO. The single, double, and multi-layer Graphene can also be differentiated by their raman fingerprints[39]. The raman spectra of the GO and rGO are shown in Fig.6 (a, and b). It shows that the D and G bands of GO observed at wave number of 1355 and $1605 \mathrm{~cm}^{-1}$ are shifted to the 1340 and $1586 \mathrm{~cm}^{-1}$ in case of rGO sheets.

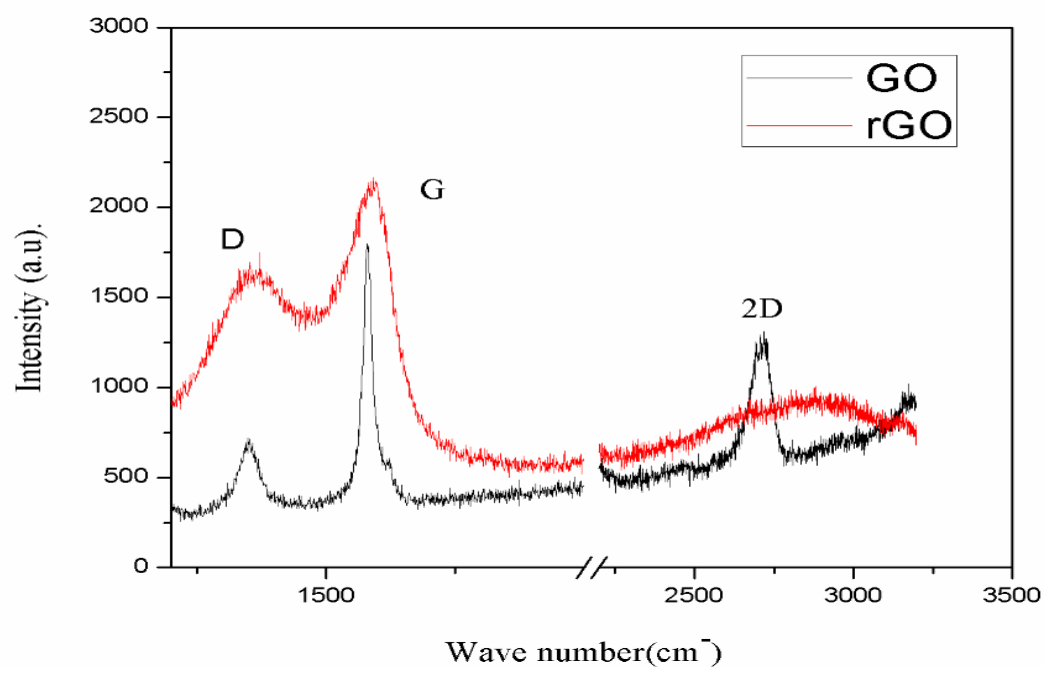


Fig.6. Raman spectra of Graphene oxide and reduced Graphene oxide

The G-band arises from the stretching of the C-C bond in graphitic materials and is ordinary for all $\mathrm{sp}^{2}$ carbon systems. The $\mathrm{D}$-mode is originated by disordered $\mathrm{sp}^{2}$-hybridization, defect and some impurity structure of GO. The relative intensity ratio of D and G band of GO is about 0.36 , while in case ofrGO, the value is about to 0.77 . The higher value of intensity ratio in case of rGO suggests, the presence of defect that remained even after the removal of large amount of oxygen containing functional groups [40]. This further confirms that GO is reduced in rGO. The presence of $2 \mathrm{D}$ band in the GO located at wave number of $2623 \mathrm{~cm}^{-1}$ is overtone of $\mathrm{D}$ band that can be attributed to a second order two phonon of Raman process. This band is useful to determine the number of layer and thickness of graphene layer. Intensity ratio of $2 \mathrm{D}$ band $\mathrm{G}$ band is about 0.75 that corresponds to 5-7 number of graphene layer which is consistent with TEM image shown Figure 3d. The 2D band in the Graphene oxide also indicates that all graphite layers have been oxidized, as shown by the XRD results in Fig 5. The absence of $2 \mathrm{D}$ band in rGO spectra indicates that removal of oxygen functionality in the GO by chemical and thermal reduction[39]. The FT-IR spectroscopy was utilized to confirm the process for the preparation Graphene oxide and reduced graphene oxide. Fig. 7 exhibits FTIR spectra of GO and rGO.

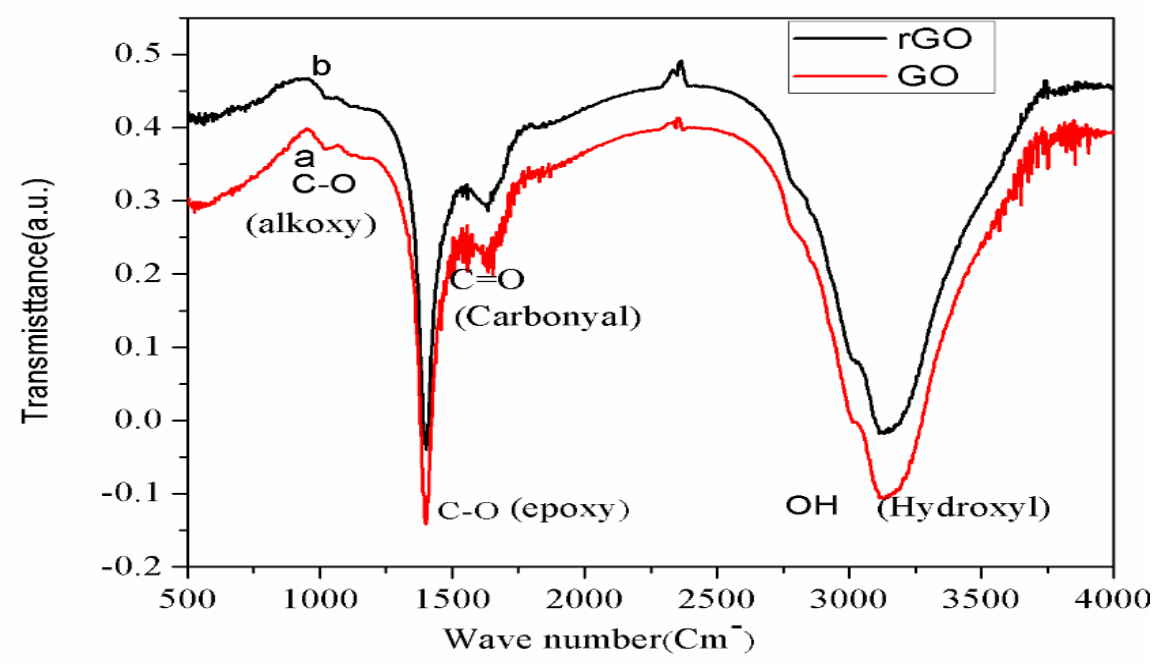


Fig.7 FTIR spectra of graphene oxide and reduced graphene oxide

The peaks located at $3130 \mathrm{~cm}^{-1}$ and $1406 \mathrm{~cm}^{-1}$ are showing the stretching and bending of the widespread $\mathrm{O}-\mathrm{H}$ groups in the sample. The characteristic peaks of oxygen are located at wave number of $1124 \mathrm{~cm}^{-1}, 1640 \mathrm{~cm}^{-1}$ which are corresponding to $\mathrm{C}-\mathrm{O}$ (epoxy or alkoxy), and $\mathrm{C}=\mathrm{O}$ in carboxylic acid, respectively. This suggests that the oxidation of graphite took place during synthesis processing by modified Hummers method which is consistent with existing literature[41-43]. It is also interesting to note that Fig.7 the intensity of $\mathrm{O}-\mathrm{H}, \mathrm{C}-\mathrm{O}$ (epoxy or alkoxy), $\mathrm{C}=\mathrm{O}$ (carboxylic acid) peak in $\mathrm{GO}$ is lesser in comparison to reduced graphene oxide.

\section{HYDROGEN STORAGE PERFORMANCE}

Hydrogen storage isotherm of $\mathrm{GO}$ and $\mathrm{rGO}$ is recorded upto a pressure of 80bar at room temperature and shown in Fig 8. Commencing the results, it was observed that hydrogen absorption in the GO is much higher than that of rGO. The rGO absorbs a small amount of molecular hydrogen $1.34 \mathrm{wt} \%$ at 80 bar .However, significant increase in $\mathrm{H}_{2}$ uptake was observed in thegraphene oxide at same pressure.

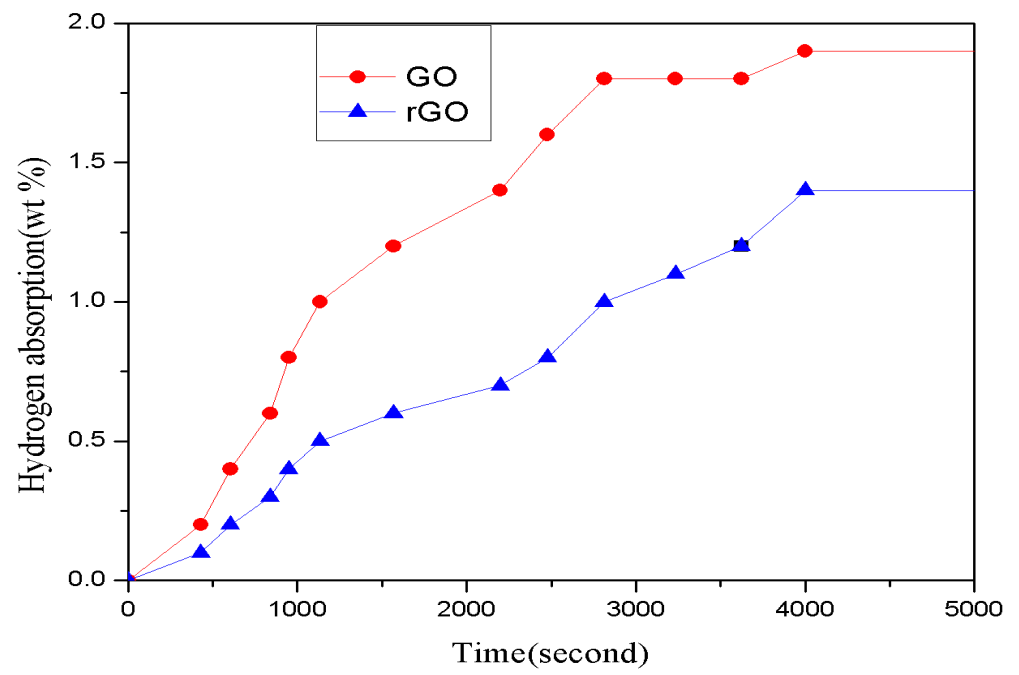


Fig.8. Hydrogen uptake by graphene oxide and reduced graphene oxide

The increase $\mathrm{H}_{2}$ uptake (1.90wt\%)capacity of GO as compared to rGO can therefore be attributed to the oxygen functional group via chemical oxidation, that provide the spacers in between the graphene layer. But in the case of rGO, these functional groups are removed by the chemical reduction. So, one may note that shortage of oxygen functionalities in rGO obstruct the adsorption of hydrogen molecules on the surface of the carbon sheets nano sheet.

\section{CONCLUSION}

Experimental results related to synthesis of GO and $\mathrm{rGO}$ sample by the modified hummer'smethod and characterized using SEM, TEM, XRD, FTIR and Raman spectroscopy, are presented.Hydrogen storage performance of $\mathrm{GO} / \mathrm{rGO}$ at room temperature and high pressure( 80 bar) is measured by the ingeniously designed high pressure volumetric hydrogen storage system. The calculated value of the hydrogen storage capacity for the GO/rGOis about to $1.90 \mathrm{wt}$. \% and $1.34 \mathrm{wt} . \%$, respectively at room temperature.The results are explained on the basis of increase in inert-layer spacing due to presence of oxygen functional groups.

\section{ACKNOWLEDGMENTS:}

One of the authors (Rajveer Singh Rajaura) gratefully acknowledges the financial support by UGC funded project (Reference number- 41-903/2012(SR)/UGC ),New Delhi, for providing financial assistance. 


\section{REFERENCE}

1. Houghton, J.T. Climate change 2001: the scientific basis; contribution of Working Group I to the third assessment report of the Intergovernmental Panel on Climate Change Cambridge: Cambridge Univ. Press. 2001.

2. Satyapal, S., et al., The US Department of Energy's National Hydrogen Storage Project: Progress towards meeting hydrogen-powered vehicle requirements. Catalysis Today, 2007. 120(3-4): p. 246-256.

3. Jain, I.P., C. Lal, and A. Jain, Hydrogen storage in Mg: A most promising material. International Journal of Hydrogen Energy, 2010. 35(10): p. 5133-5144.

4. Fichtner, M., Nanotechnological aspects in materials for hydrogen storage. Advanced Engineering Materials, 2005. 7(6): p. 443-455.

5. Schlapbach, L. and A. Zuttel, Hydrogen-storage materials for mobile applications. Nature, 2001. 414(6861): p. 353-8.

6. Schlapbach, L. and A. Zuttel, Hydrogen-storage materials for mobile applications. Nature, 2001. 414(6861): p. 353-358.

7. Grochala, W. and P.P. Edwards, Thermal decomposition of the non-interstitial hydrides for the storage and production of hydrogen. Chem Rev, 2004. 104(3): p. 1283-316.

8. Sakintuna, B., F. Lamari-Darkrim, and M. Hirscher, Metal hydride materials for solid hydrogen storage: A review. International Journal of Hydrogen Energy, 2007. 32(9): p. 1121-1140.

9. Bardhan, R., et al., Magnesium nanocrystal-polymer composites: A new platform for designer hydrogen storage materials. Energy \& Environmental Science, 2011. 4(12): p. 4882-4895. 
10. Dillon, A.C. and M.J. Heben, Hydrogen storage using carbon adsorbents: past, present and future. Applied Physics a-Materials Science \& Processing, 2001. 72(2): p. 133-142.

11. Spyrou K, G.D., and Rudolfa P., Hydrogen Storage in Graphene-Based Materials: Efforts Towards Enhanced Hydrogen Absorption. ECS Journal of Solid State Science and Technology, 2013. 2(10): p. 3160-3169.

12. Novoselov, K.S., et al., Electric field effect in atomically thin carbon films. Science, 2004. 306(5696): p. 666-9.

13. Lee, C., et al., Measurement of the elastic properties and intrinsic strength of monolayer graphene. Science, 2008. 321(5887): p. 385-8.

14. Geim, A.K. and K.S. Novoselov, The rise of graphene. Nat Mater, 2007. 6(3): p. 183-91.

15. Wang, L., et al., Graphene oxide as an ideal substrate for hydrogen storage. ACS Nano, 2009. 3(10): p. 2995-3000.

16. Abergel, D.S.L., et al., Properties of graphene: a theoretical perspective. Advances in Physics, 2010. 59(4): p. 261-482.

17. Pumera, M., Graphene-based nanomaterials for energy storage. Energy \& Environmental Science, 2011. 4(3): p. 668-674.

18. Srinivas, G., et al., Synthesis of graphene-like nanosheets and their hydrogen adsorption capacity. Carbon, 2010. 48(3): p. 630-635.

19. Aboutalebi, S.H., et al., Enhanced Hydrogen Storage in Graphene Oxide-MWCNTs Composite at Room Temperature. Advanced Energy Materials, 2012. 2(12): p. 14391446.

20. Ghosh, A., et al., Uptake of H-2 and CO2 by graphene. Journal of Physical Chemistry C, 2008. 112(40): p. 15704-15707. 
21. Burress, J.W., et al., Graphene oxide framework materials: theoretical predictions and experimental results. Angew Chem Int Ed Engl, 2010. 49(47): p. 8902-4.

22. Kim, B.H., et al., Thermally modulated multilayered graphene oxide for hydrogen storage. Phys Chem Chem Phys, 2012. 14(4): p. 1480-4.

23. Hong, W.G., et al., Agent-free synthesis of graphene oxide/transition metal oxide composites and its application for hydrogen storage. International Journal of Hydrogen Energy, 2012. 37(9): p. 7594-7599.

24. Marcano, D.C., et al., Improved synthesis of graphene oxide. ACS Nano, 2010. 4(8): p. 4806-14.

25. Hummers W. S., O.R.E., Preparation of graphitic oxide. Journal of the American Chemical Society, 1958. 80(6): p. 1339-1958.

26. Ren, P.G., et al., Temperature dependence of graphene oxide reduced by hydrazine hydrate. Nanotechnology, 2011. 22(5): p. 055705.

27. Sharma V., R.R.S., Sharma P.K., Srivastava Subodh V., Sharma S. S. and Vijay Y. K. . Optical and morphological properties of graphene sheets decorated with ZnO nanowires via polyol enhancement. in AIP Conference Proceedings 2014. Patiyala University, Thapar, India.

28. Lachawiec, A.J., Jr., T.R. DiRaimondo, and R.T. Yang, A robust volumetric apparatus and method for measuring high pressure hydrogen storage properties of nanostructured materials. Rev Sci Instrum, 2008. 79(6): p. 063906.

29. Dikin, D.A., et al., Preparation and characterization of graphene oxide paper. Nature, 2007. 448(7152): p. 457-60. 
30. Li, X., et al., Large-area synthesis of high-quality and uniform graphene films on copper foils. Science, 2009. 324(5932): p. 1312-4.

31. Liang, X., et al., Toward clean and crackless transfer of graphene. ACS Nano, 2011. 5(11): p. 9144-53.

32. Ismach, A., et al., Direct chemical vapor deposition of graphene on dielectric surfaces. Nano Lett, 2010. 10(5): p. 1542-8.

33. Gass, M.H., et al., Free-standing graphene at atomic resolution. Nat Nanotechnol, 2008. 3(11): p. 676-81.

34. Meyer, J.C., et al., Imaging and dynamics of light atoms and molecules on graphene. Nature, 2008. 454(7202): p. 319-22.

35. Meyer, J.C., et al., Direct imaging of lattice atoms and topological defects in graphene membranes. Nano Lett, 2008. 8(11): p. 3582-6.

36. Shen, J.F., et al., One step hydrothermal synthesis of TiO2-reduced graphene oxide sheets. Journal of Materials Chemistry, 2011. 21(10): p. 3415-3421.

37. Wang, S., et al., Wettability and surface free energy of graphene films. Langmuir, 2009. 25(18): p. 11078-81.

38. Kulriya, P.K., et al., Setup for in situ x-ray diffraction study of swift heavy ion irradiated materials. Rev Sci Instrum, 2007. 78(11): p. 113901.

39. Casiraghi, C., et al., Raman fingerprint of charged impurities in graphene. Applied Physics Letters, 2007. 91(23).

40. Ferrari, A.C. and D.M. Basko, Raman spectroscopy as a versatile tool for studying the properties of graphene. Nature Nanotechnology, 2013. 8(4): p. 235-246. 
41. Paredes, J.I., et al., Graphene oxide dispersions in organic solvents. Langmuir, 2008. 24(19): p. 10560-4.

42. Bourlinos, A.B., et al., Graphite oxide: Chemical reduction to graphite and surface modification with primary aliphatic amines and amino acids. Langmuir, 2003. 19(15): p. $6050-6055$.

43. Stankovich, S., et al., Synthesis and exfoliation of isocyanate-treated graphene oxide nanoplatelets. Carbon, 2006. 44(15): p. 3342-3347. 